\title{
University Students Usage of Facebook: The Case of Obtained Gratifications and Typology of Its Users
}

\author{
Shuaa Aljasir ${ }^{1}$, Ayman Bajnaid ${ }^{1}$, Tariq Elyas ${ }^{2} \&$ Mustafa Alnawasrah ${ }^{3}$ \\ ${ }^{1}$ Faculty of Media and Communication, Communication Department, King Abdulaziz University, Jeddah, Saudi \\ Arabia \\ ${ }^{2}$ European Languages Department, King Abdulaziz University, Jeddah, Saudi Arabia \\ ${ }^{3}$ Faculty of Business \& Finance, Business Administration Department, The World Islamic Science \& Education \\ University, Amman, Jordan \\ Correspondence: Shuaa Aljasir, Faculty of Media and Communication, Communication Department, King Abdulaziz \\ University, Jeddah, Saudi Arabia. E-mail: shaljasir@kau.edu.sa
}

Received: October 27, 2017

Accepted: November 8, 2017

Online Published: November 16, 2017

doi:10.5430/jms.v8n5p30

URL: https://doi.org/10.5430/jms.v8n5p30

\begin{abstract}
This paper presents and discusses the results from the designed quantitative self-report questionnaire. It addresses two main research objectives: first, to contribute to the uses and gratifications research by exploring the gratifications that research participants who belong to an Islamic culture obtain from using Facebook, and second, to inform theoretical and empirical media and communications research through proposing a typology of users based on their obtained gratifications, usage variables, and demographic variables. The findings showed that Saudi university students obtained 11 gratifications and that there are three types of Saudi Facebook users.
\end{abstract}

Keywords: obtained gratifications, facebook, university students, social media

\section{Introduction}

Social media is one of the most popular types of applications to emerge through the technological revolution of Web 2.0, which enables users to create and exchange content (Kaplan \& Haenlein, 2010; Maqableh, Rajab, Quteshat \& Karajeh, 2015; Alalwan et al., 2016). It provides users the opportunity to broadcast their personal thoughts, share pictures or videos, express beliefs, establish relationships, and build virtual communities centred on common interests. It has also facilitated communication and resource sharing among individuals, organisations, and communities due to its flexibility and accessibility from different devices (Leung, 2014). According to Lovink (2013: 58), "Whether or not we are in the midst of yet another internet bubble, we can all agree that social media dominates the use of the internet". The ubiquity and pervasiveness with which social media platforms have been adopted worldwide and the degree to which they now occupy a significant part of individuals' daily lives make them a Petri dish for media and communication research.

Western and East Asian media and communication scholars interested in understanding why users have adopted and utilised social media platforms have indicated that social media affords users a new platform through which they can virtually engage in a wide range of activities that they perform offline. They have also highlighted that the reasons and the ways individuals utilise a certain social media platform may differ depending on their cultural milieu, given that fundamental norms differ from one culture to another (e.g., Bumgarner, 2007; Sheldon, 2008; Urista, Dong, \& Day, 2009; Hew \& Cheung, 2012; Pai \& Arnott, 2013; Alhabash, Chiang, \& Huang, 2014). Since individuals in Arab societies have a limited space to engage in offline activities in comparison with Westerners and East Asians (Miladi, 2011), there is a gap in the literature regarding what makes social media platforms popular among those Arab users who belong to non-Western cultures and the extent to which social media platforms may be utilised differently in these cultural contexts. Thus, the current research seeks to fill this gap in knowledge through investigating why Saudi university students use Facebook.

The paper begins by discussing sample demographics, characterising the sample and the extent to which this sample is representative of the total population of Saudi university students. The following sections explore Facebook usage and obtained gratifications before presenting a typology of Saudi university student Facebook users. The final 
section presents the conclusions of the research.

\section{Demographic Background of the Sample}

Reviewing the uses and gratifications literature indicates that gender, academic major, and economic status are the principal factors that influence the gratifications that users obtain from using Facebook. For instance, research by Joinson (2008) and Park, Kee, \& Valenzuela (2009) showed gender differences in the gratifications obtained from using Facebook. Zhang, Tang, \& Leung (2011) covered the influence of personal income. Mishra et al. (2012) considered academic major as a key factor in impacting Facebook usage. As previous studies have shown that these factors were relevant to Facebook usage, the expectation is that they will also influence Saudi students. Table 1 summarises the participants' demographic variables.

Table 1. Demographic variables of the participants

\begin{tabular}{|c|c|c|c|}
\hline Characteristic & Category & Frequency & Percent \\
\hline \multirow{2}{*}{ Gender } & Male & 188 & 50.5 \\
\hline & Female & 184 & 49.5 \\
\hline \multirow{2}{*}{ Major } & Science & 229 & 61.6 \\
\hline & Humanities \& Administration & 143 & 38.4 \\
\hline \multirow{4}{*}{ Living Status } & With parents & 309 & 83.1 \\
\hline & By Self & 32 & 8.6 \\
\hline & With Roommates & 26 & 7.0 \\
\hline & With a Spouse & 5 & 1.3 \\
\hline \multirow{4}{*}{ Relationship Status } & Single & 349 & 93.8 \\
\hline & Engaged & 18 & 4.9 \\
\hline & Married & 5 & 1.3 \\
\hline & Divorced & 0 & -- \\
\hline \multirow{4}{*}{ Type of Residence } & House & 201 & 54.0 \\
\hline & Apartment & 151 & 40.6 \\
\hline & Other - Dorm & 17 & 4.6 \\
\hline & Other - Rented Room & 3 & 0.8 \\
\hline \multirow[t]{8}{*}{ Parental Income } & Under SA 1,500 & 15 & 4.0 \\
\hline & SA $1,501-3,999$ & 30 & 8.1 \\
\hline & SA 4,000-6,999 & 45 & 12.1 \\
\hline & SA 7,000-9,999 & 59 & 15.9 \\
\hline & SA $10,000-14,999$ & 63 & 16.8 \\
\hline & SA $15,000-20,000$ & 61 & 16.4 \\
\hline & SA $20,000+$ & 69 & 18.6 \\
\hline & Do not know & 30 & 8.1 \\
\hline \multirow[t]{8}{*}{ Father's Education } & Uneducated & 20 & 5.4 \\
\hline & Elementary school & 30 & 8.1 \\
\hline & Middle school & 45 & 12.1 \\
\hline & High School & 88 & 23.7 \\
\hline & Bachelor Degree & 175 & 47.0 \\
\hline & Other-Graduate Diploma & 5 & 1.3 \\
\hline & Other - Master & 4 & 1.1 \\
\hline & Other-Doctorate & 5 & 1.3 \\
\hline \multirow[t]{8}{*}{ Mother's Education } & Uneducated & 35 & 9.4 \\
\hline & Elementary school & 46 & 12.4 \\
\hline & Middle school & 52 & 14.0 \\
\hline & High School & 94 & 25.2 \\
\hline & Bachelor Degree & 135 & 36.3 \\
\hline & Other - Graduate Diploma & 4 & 1.1 \\
\hline & Other - Master & 4 & 1.1 \\
\hline & Other-Doctorate & 2 & 0.5 \\
\hline
\end{tabular}


From Table 1, it can be seen that of the 372 respondents, the gender makeup of the sample was basically equal: $50.5 \%$ male and $49.5 \%$ female. This is in line with Saudi educational policy introduced in 1978 that emphasises providing equal educational opportunities to both genders (Ministry of Higher Education, 2013). According to AlMunajjed (2008), education is a field in which females have experienced noticeable advancement in Saudi Arabia, with the Saudi state investing significant resources to improve females' access to education. A recent Ministry of Higher Education statistical report indicates that in 2011 (the year this phase of the research was conducted), the students enrolled at Saudi universities were 55\% male and 45\% female (Ministry of Higher Education, 2013). This percentage roughly matches that of the current sample, as both genders were approximately equally represented. However, it should be noted that this report does not indicate whether this equality extends to the majors they were pursuing.

A breakdown of the respondents by academic discipline revealed that 229 respondents $(61.6 \%)$ were majoring in science, and the remaining $143(38.4 \%)$ were majoring in the humanities or administration. This breakdown corresponded with the sections of the respondents who were taking a basic communication course: there were 63 course sections for science students and 37 sections for humanities/administration students. The higher number of science students is consistent with Saudi Arabia's five-year plan to promote enrolment in science majors in order to provide students with the qualifications the labour market requires (Baki, 2004).

In relation to residence, it is the Saudi norm for individuals to live with their families until they are married. According to recent statistics, the average age at which Saudis leave home and marry is 30 for males and 24 for females (Salam, 2013). In accordance with these norms, the majority of participants in the current sample lived with their parents $(\mathrm{n}=309,83.1 \%)$.

Although Saudi university students receive monthly grants from their universities, the majority of Saudis continue to depend on their families until they become employed or, in the case of women, get married (Al-Khateeb, 1998). The answers to the question about parental income were relatively normally distributed, ranging from 15 respondents (4.0\%) with incomes of SA 1,500 or less to 69 respondents (18.6\%) with incomes of SA 20,000 or more. This result illustrates that parental incomes ranged from relatively low to relatively high.

From Table 1, it can be seen that the educational attainments of both parents showed a similar pattern, as the frequency in each category increased with each successive educational level through the university level. Nevertheless, fathers had proportionally higher levels of education than mothers. This is consistent with recent statistics indicating that, although progress has been made towards educational gender parity in Saudi Arabia, there is still an educational gap among older generations that favours males (UNESCO, 2011). Reviewing the profile of the sample, it appears that it can be considered a representative sample for the population of Saudi university students as a whole. The data obtained from this section assists in forming a typology of Facebook users.

\section{Facebook Usage}

This section considers the sample's usage patterns, such as whether the students were early or late adopters of Facebook and whether they are heavy or light users. It also assesses the sizes of their online friendship networks, their preferred locations and devices for accessing Facebook, and if they disclose their names and photos on their profiles. As with the demographic variables, examining these usage variables helped in determining whether Saudi university students differ in the gratifications they obtain from Facebook according to their usage patterns, in order to provide a comprehensive typology of Facebook users.

\subsection{Years of Experience and Time Spent on Facebook}

While the Millennial Generation has been the focus of most of the recent Western studies in the field of social media and particularly Facebook, little attention has been given to this generation in the Arab world in general and in Saudi Arabia in particular. The Millennial Generation, also known as Generation Y, Generation Next, the Net Generation, Digital Natives, or Generation Me, is defined as those born between 1981 and 2000 (Pew Internet and American Life Project, 2010). This generation is characterised as having grown up with technology; they are the main consumers of the Internet and often the first to embrace technological innovations (McCorkindale, DiStaso, \& Sisco, 2013).

Social media usage is one of the most prominent characteristics of the Millennial Generation (Phillips, 2010). As $70 \%$ of the population in the Kingdom of Saudi Arabia belong to the Millennial Generation (UNICEF, 2012), the current research focuses on this generation and on university students in particular. This section presents the results and a discussion of the responses regarding Saudi university students' years of experience and time spent on Facebook. The descriptive results of these two variables are shown in Table 2. 
Table 2. Years of experience of using facebook and time spent on facebook

\begin{tabular}{ccccc}
\hline Years of & $<\mathbf{1}$ year & $\mathbf{1 - 2}$ years & $\mathbf{2 . 1 - 3}$ years & $>$ 3 years \\
\cline { 2 - 5 } Experience & $87(23.4 \%)$ & $133(35.7 \%)$ & $68(18.3 \%)$ & $84(22.6 \%)$ \\
\hline Time Spent & Mean & Std. Deviation & Minimum & Maximum \\
\cline { 2 - 5 }$($ min. per day) & 152 & 131.4 & 5.00 & 850.00 \\
\hline
\end{tabular}

Of the respondents who use Facebook, $22.6 \%$ had been using it for more than three years, $18.3 \%$ from two to three years, $35.7 \%$ from one to two years, and $23.4 \%$ for less than a year. Given that the sample comprised university students who were freshmen at the time of the questionnaire phase, it seems that about $40 \%$ of the respondents began using Facebook during high school while the majority of the sample started using it after 2009 (the year that the Arabic Facebook interface launched) and could be classed as early adopters. This is consistent with previous literature that argues that interest in using Facebook in the Arab world increased after the unveiling of the Arabic interface (Arab Social Media Report, 2011).

Respondents were also asked to report how much time they spent on Facebook in order to evaluate the degree of their engagement with it. To help improve the accuracy of the data, students were encouraged to keep track of the time they spent on Facebook for a week before completing the questionnaire and to calculate the average. The result showed a great deal of variation, from 5 minutes to about 14 hours per day (i.e., 850 minutes). It reveals an average of about two and a half hours (152 minutes) per day spent on Facebook.

Given that the students were asked about the active time they spent on Facebook and not the time they were logged on to it, spending two and a half hours daily on Facebook represents a significant time commitment for a university student and is higher than that reported by American university students, as revealed by Bonds-Raacke \& Raacke (2010) (two hours per day), Chou \& Edge (2012) (about an hour per day), and Pempek, Yermolayeva, \& Calvert (2009) (half an hour per day). This result is significant because it would seem that, for some students, Facebook usage takes up a large proportion of their time and that they are highly active on it. This emphasises the importance of understanding the gratifications students gain from using its platform and their online usage behaviours.

Table 3. Gender differences in years of experience and time spent on facebook

\begin{tabular}{|c|c|c|c|c|c|}
\hline \multirow{2}{*}{ Years of Experience } & \multicolumn{2}{|c|}{ Males } & \multicolumn{2}{|c|}{ Females } & Statistic \\
\hline & \multicolumn{2}{|c|}{$N(\%)$} & \multicolumn{2}{|c|}{$N(\%)$} & Chi-square \\
\hline Less than 1 year & \multicolumn{2}{|c|}{$42(22.3 \%)$} & \multicolumn{2}{|c|}{$45(24.5 \%)$} & $\chi^{2}(3)=3.002$, \\
\hline 1 to 2 years & \multicolumn{2}{|c|}{$74(39.4 \%)$} & \multicolumn{2}{|c|}{$59(32.1 \%)$} & $\mathrm{p}=.391$ \\
\hline 2.1 to 3 years & \multicolumn{2}{|c|}{$35(18.6 \%)$} & \multicolumn{2}{|c|}{$33(17.9 \%)$} & \\
\hline More than 3 years & \multicolumn{2}{|c|}{$37(19.7 \%)$} & \multicolumn{2}{|c|}{$47(25.5 \%)$} & \\
\hline \multirow{3}{*}{$\begin{array}{c}\text { Time Spent on } \\
\text { Facebook } \\
\text { (min. per day) }\end{array}$} & \multicolumn{2}{|c|}{ Males } & \multicolumn{2}{|c|}{ Females } & Statistic \\
\hline & Mean $(S D)$ & Mean Rank & Mean $(S D)$ & Mean Rank & Mann-Whitney $U$ \\
\hline & $154.00(126.31)$ & 191.92 & $150.65(136.75)$ & 180.96 & $\begin{array}{c}U=16277.5 \\
\mathrm{p}=.321\end{array}$ \\
\hline
\end{tabular}

Gender differences in years of experience and time spent on Facebook were analysed using chi-square test of independence. Results of the analysis are presented in Table 3. Interestingly, males and females did not differ in their years of Facebook experience. A Mann-Whitney $U$ test was used to determine differences in time spent on Facebook according to gender. Due to the skewed nature of the time variables, the Mann-Whitney $U$ provides the non-parametric version of the t-test and is the most suitable alternative when examining ordinal variables between group differences. Males and females did not differ in the amount of time spent per day on Facebook. Although previous research indicates that Saudi parents are more cautious about letting their daughters use the Internet in general and Facebook in particular (Oshan, 2007; Khannous, 2011), it seems from these findings that this caution did not affect the current sample's usage time.

\subsection{Facebook Network Size}

Facebook provides the opportunity to expand individuals' social networks through a process called 'friending', in which Facebook users can construct online profiles and gather friends on a reciprocal basis (Lewis \& West, 2009). 
According to Condella (2012), the popularity of the Facebook friendship phenomenon is evidenced by the introduction of the word 'friending' into the English language. Different clusters of real-life friends have been identified in the previous literature. For example, McCarty (2002) argues that individuals have approximately six types of network clusters: family, neighbours, work colleagues, previous work colleagues, school friends, and contacts via a third person. On the Facebook platform, all of these different categories are flattened into one single cluster of 'friends' (Boyd, 2007). The findings about Saudi university students' Facebook network sizes and their variance by gender using the chi-square test are presented in Table 4.

Table 4. Facebook network size

\begin{tabular}{|c|c|c|c|c|}
\hline Facebook Network Size & $\leq \mathbf{5 0}$ & $51-250$ & 251-500 & $501+$ \\
\hline$(\mathrm{N}=372)$ & $149(40.1 \%)$ & $156(41.9 \%)$ & $40(10.7 \%)$ & $27(7.3 \%)$ \\
\hline Differences in Network Size & $\begin{array}{l}\text { Males } \\
\mathbf{N}(\%) \\
\end{array}$ & & $\begin{array}{c}\text { Females } \\
\mathbf{N}(\%) \\
\end{array}$ & Chi-square test \\
\hline 50 or fewer & $69(36.7 \%)$ & & $80(43.5 \%)$ & \multirow{4}{*}{$\chi^{2}=10.23(1), p=.017$} \\
\hline 51 to 250 & $75(39.9 \%)$ & & $81(44.0 \%)$ & \\
\hline 251 to 500 & $23(12.2 \%)$ & & $17(9.2 \%)$ & \\
\hline More than 500 & $21(11.2 \%)$ & & $6(3.3 \%)$ & \\
\hline
\end{tabular}

From Table 4, it can be seen that the majority of the respondents (82\%) reported having up to 250 Facebook friends, and almost 18\% had more than that number. Sustaining meaningful relationships with such a large number of people may be difficult offline. The average size of Saudi university students' networks in this research is in line with previous findings derived from Western university students. Previous studies have presented averages of between 151 and 272 friends: 272 (Boogart, 2006), 151-200 and 201-250 (Ellison, Steinfield, \& Lampe, 2007), 246 (Walther, et al. 2008) and 224 friends (Ross, et al. 2009).

In terms of gender differences in Facebook network size, analysis of responses reveals that there are significantly more males $(n=21)$ than females $(n=6)$ with over 500 Facebook friends. This result contradicts the findings of a study among American students (Pempek, Yermolayeva, \& Calvert, 2009) that reported that females have significantly more friends than males. Such a difference could be explained in light of the gender roles of Saudi males and females.

\subsection{Facebook Accessibility}

In addition to personal computers, digital mobile devices play a powerful role in the lives of many individuals today. Such diffusion allows for social media platforms to be accessed by users via their laptops, smart phones, and tablets, which provide on-demand, direct, flexible, and effective methods of engagement and communication (Khaddage \& Reed, 2013). Participants' responses to the questions about the places and devices through which they accessed Facebooks were analysed using descriptive statistics and chi-square test to identify any differences based on gender. The results are shown in Tables 5, 6, 7, and 8 .

Table 5. Facebook accessing devices

\begin{tabular}{lcc}
\hline \multicolumn{1}{c}{ Variable } & N & Percent of Cases* \\
\hline Personal laptop & 304 & $81.7 \%$ \\
\hline Smart Phone & 162 & $43.5 \%$ \\
\hline Personal Computer & 63 & $16.9 \%$ \\
\hline Shared Computer & 30 & $8.1 \%$ \\
\hline Tablet & 0 & $0 \%$ \\
\hline
\end{tabular}

* Respondents were allowed to tick more than one box 
Table 6. Differences between males and females in facebook accessing devices

\begin{tabular}{lccc}
\hline \multirow{2}{*}{ Variable } & Male & Female & Statistic \\
\cline { 2 - 4 } & $\mathbf{N}(\boldsymbol{\%})$ & $\mathbf{N}(\boldsymbol{\%})$ & FET p-value (2-sided) \\
\hline Personal Laptop & $157(83.5)$ & $147(79.9)$ & $\chi^{2}(1)=.815, \mathrm{p}=.367$ \\
\hline Smart Phone & $83(44.1)$ & $79(42.9)$ & $\chi^{2}(1)=.056, \mathrm{p}=.813$ \\
\hline Personal Computer & $50(26.6)$ & $13(7.1)$ & $\chi^{2}(1)=25.214, \mathrm{p}<0.001$ \\
\hline Shared Computer & $26(13.8)$ & $4(2.2)$ & $\chi^{2}(1)=17.040, \mathrm{p}<0.001$ \\
\hline
\end{tabular}

As shown in Table 5, Facebook is accessed from multiple devices; the majority (81.7\%) use a laptop and just over $(40 \%)$ use smart phones. Few respondents used a personal desktop computer $(16.9 \%)$ or a shared desktop computer $(8.1 \%)$. None of the respondents accessed Facebook from a tablet. While there were no significant gender differences in Facebook access via laptops or smart phones, males were significantly more likely than females to access Facebook through personal or shared computers (26.6\% and $13.8 \%$ for males versus $7.1 \%$ and $2.2 \%$ for females).

The analysis indicates a high level of mobile technological engagement, enabling Facebook to be accessed anywhere and at any time. The focus groups revealed more detailed usage patterns, with smart phones used to view updates and other devices used to share content, due to the limited features available in the mobile version of Facebook. In general, Saudi students' access of Facebook is similar to that of Western students. For instance, a study by Barkhuus \& Tashiro (2010) found that $88.9 \%$ of their sample of American students accessed Facebook through a laptop and $44.4 \%$ of students accessed it through their phones. This pattern was confirmed by a more recent US-based study (Gomes, Matos, \& Duarte, 2014), which indicated that students are most likely to access Facebook through their laptops, followed by smart phones, desktop computers, and finally, tablets.

Table 7. Preferred locations to access facebook

\begin{tabular}{lcc}
\hline \multicolumn{1}{c}{ Variable } & Responses & Percent of Cases* \\
\hline Home & 355 & $95.4 \%$ \\
\hline University & 65 & $17.5 \%$ \\
\hline Internet Café & 54 & $14.5 \%$ \\
\hline Friend's home & 48 & $12.9 \%$ \\
\hline Other & 9 & $2.4 \%$ \\
\hline
\end{tabular}

* Respondents were allowed to tick more than one box

Table 8. Gender differences in preferred locations to access facebook

\begin{tabular}{lccc}
\hline \multirow{2}{*}{ Variable } & Male & Female & Statistic \\
\cline { 2 - 4 } & $\mathbf{N}(\boldsymbol{\%})$ & $\mathbf{N}(\boldsymbol{\%})$ & Chi-square \\
\hline Home & $181(96.3)$ & $174(94.6)$ & $\chi^{2}(1)=0.625, \mathrm{p}=.429$ \\
\hline University & $37(19.7)$ & $28(15.2)$ & $\chi^{2}(1)=1.285, \mathrm{p}=.257$ \\
\hline Internet Café & $47(25.0)$ & $7(3.8)$ & $\chi^{2}(1)=33.666, \mathrm{p}<.001$ \\
\hline Friend's Home & $33(17.6)$ & $15(8.2)$ & $\chi^{2}(1)=7.313, \mathrm{p}=.007$ \\
\hline Other & $3(1.6)$ & $6(3.3)$ & $\chi^{2}(1)=1.092, \mathrm{p}=.333^{*}$ \\
\hline
\end{tabular}

$* 2$ cells $(50 \%)$ with expected cell count $<5$. Exact significance reported.

From Table 7, it appears that almost all respondents prefer to access Facebook from home (95.4\%). A few respondents accessed their Facebook accounts from the university (17.5\%), Internet cafés $(14.5 \%)$, and friends' homes (12.9\%). For those who answered 'other', they reported that they log into their accounts whenever they have free Internet access. These results are consistent with Barkhuus \& Tashiro's (2010) study of American university students, who mainly prefer to access Facebook at home followed by other places such as the university campus, coffee shops, or libraries.

Regarding gender differences in the locations used to access Facebook, the results revealed that males were more likely than females to access Facebook from Internet cafés (25.0\% compared to 3.8\%, respectively). Males were also 
more likely than females to access Facebook from a friend's home (17.6\% compared to $8.2 \%$, respectively). This may reflect Saudi norms, as females generally stay at home more than males (Madini, 2012).

\subsection{Facebook Profile Names and Photos}

The practice of sharing an individual's name is rooted in rituals of relationship development. Stating an individual's name is considered an introductory sign to indicate politeness and openness (Boyd, 2012; Obeidat, Tarhini, \& Aqqad, 2017). While individuals' names in Western contexts are identifiers for individuals to share when introducing one another, often providing little additional social information beyond what the individual's presence already conveys, names in the Arab world signal their socioeconomic positions and link their holders to the values and traditions of their family origins (Samin, 2008). Despite their heavy weight in identifying individuals' positions in society, there is a gap in the literature regarding the usage of real names by Arab Facebook users.

Previous studies on disclosure of real names on Facebook suggest that individuals from many different cultures largely tend to share their real names on their Facebook profiles. For instance, Taraszow et al. (2008) found that their entire Cypriot sample $(\mathrm{n}=131)$ used their real names on Facebook. In studies of American university students, Debatin et al. (2009) $(n=119)$ and Tufekci $(2012)(n=450)$ report that about $91 \%$ of American university students use their real names on their Facebook profiles. A cross-cultural study comparing American and Northwest African cultures by Veltri \& Elgarah (2009) reported that all the respondents in their American sample ( $\mathrm{n}=15)$ and $93 \%$ of the Moroccan sample $(n=30)$ indicated that they provided their real names (first and last) on Facebook. The remaining 7\% of the Moroccan sample provided only their first names. Similarly, another cross-cultural study (Tung \& Scott, 2012) showed that the majority of Japanese $(\mathrm{n}=51)$ and American $(\mathrm{n}=11)$ university students disclose their real names, and that the Japanese youths in their sample are slightly more willing to reveal their names than American students (90.9\% as compared to $80.1 \%$ ).

Unlike these previous studies, in this research about one-third $(n=119,32 \%)$ of the sample concealed their real names in their profiles, while the rest of the respondents reported that they used their real names in their profiles $(\mathrm{n}=$ 253, 68.0\%). The results are shown in Table 9. This trend does not match Facebook's terms and conditions, which specify that users should not provide any false personal information on Facebook (Breyer \& Zuckerberg, 2005). However, it should be noted that Facebook has recently agreed to modify this policy to allow users to choose the name they want to display as their Facebook name (Goel, 2014).

Table 9. Facebook profile names

\begin{tabular}{ccc}
\hline Names & N (372) & Percentage \\
\hline Real name & 253 & $68.0 \%$ \\
\hline Nickname & 119 & $32.0 \%$ \\
\hline
\end{tabular}

A chi-square test of associations was used to show whether there were any gender differences in Facebook name usage. Significant differences were found in the responses regarding Facebook names $(\chi 2=33.78, \mathrm{p}<.001)$, with more males $(81.9 \%)$ using their real name than females (53.8\%) (see Table 10). This finding could be interpreted in light of Saudi Islamic culture, as Saudi social norms encourage males to be proud of their names and origins, while it is considered inappropriate to mention a female's name in a male gathering - either physical or virtual (Heng, 2009; Noor Elahi, 2010).

Table 10. Differences between males and females in their facebook names

\begin{tabular}{cccc}
\hline \multirow{2}{*}{ Variable } & Males & Females & Statistic \\
\cline { 2 - 4 } & $N(\%)$ & $N(\%)$ & Chi-square \\
\hline Real name & $154(81.9 \%)$ & $99(53.8 \%)$ & $\chi^{2}(1)=33.78$, \\
\hline Nickname & $34(18.1 \%)$ & $85(46.2 \%)$ & $\mathrm{p}<.001$ \\
\hline
\end{tabular}

Hum et al. (2011) indicate that the profile photo is considered one of the most informative aspects of self-disclosure or image building. The profile photo is the default photo that Facebook users select to identify them. Western studies of Facebook confirm that males and females are equally likely to display their personal photos as profile photos. For instance, $98.7 \%$ of the sample of both male and female university students in a Canadian study (Young \& Quan-Haase, 2009) reported that they are likely to post an image of themselves. American studies (Stern \& Taylor, 
2007; Debatin, et al 2009; Hum, et al. 2011) also indicate that over $74 \%$ of the students in their samples reported that their Facebook photos were exact representations of themselves. A Cypriot study by Taraszow et al. (2008) revealed that $97 \%$ of the youths in their sample publish their real photos.

On the contrary, about two-thirds of the respondents in the current research indicated that they did not post a real photo $(n=249,66.9 \%)$, while only one-third used a real photo of themselves $(n=123,33.1 \%)$. Comparing male and female students' choices of profile pictures indicates significant gender differences, with more males (60.1\%) using their real photo than females (5.4\%) (see Tables 11 and 12).

Table 11. Facebook profile photos

\begin{tabular}{ccc}
\hline Variable & $\mathbf{N}(\mathbf{3 7 2})$ & \% \\
\hline Real photo & 123 & $33.1 \%$ \\
\hline Symbolic photos & 249 & $66.9 \%$ \\
\hline
\end{tabular}

Table 12. Differences between males and females in their facebook photos

\begin{tabular}{cccc}
\hline \multirow{2}{*}{ Variable } & Males & Females & Statistic \\
\cline { 2 - 4 } & $N(\%)$ & $N(\%)$ & Chi-square \\
\hline Real photo & $113(60.1 \%)$ & $10(5.4 \%)$ & $\chi^{2}(1)=125.59$, \\
\hline Symbolic photos & $75(39.9 \%)$ & $174(94.6 \%)$ & $\mathrm{p}<.001$ \\
\hline
\end{tabular}

This interesting result mirrors the offline Saudi tradition of hijab. A recent cross-cultural study of seven Islamic countries (Moaddel, 2013) confirms that Saudi females use the most conservative hijab, which obligates females to cover their entire faces. This may explain why most Saudi female respondents use symbolic photos rather than their real photos.

\section{Facebook Obtained Gratifications and Typology of Users}

Uses and gratifications theory is based on the premise that media users are purposive and goal-oriented (Rubin 2009). It assumes that users are making a conscious and active choice about what they want to achieve when they access media tools. The following section illustrates and discusses the gratifications that Saudi university students obtain from using Facebook, in order to address the first objective of this research. This section also focuses on the typology of the Saudi Facebook users.

\subsection{Facebook-Obtained Gratification Factors}

Saudi university students were asked to rate the degree of gratification they obtained from using Facebook on a 5-point scale. The mean, median, and standard deviation for each item were calculated. From the 40 ranked gratifications, the highest means were associated with relationship formation and maintenance and the lowest for information seeking and e-commerce (i.e., buying and selling).

The responses were factor analysed to examine whether one broad category or several more specific categories were required to describe the item set. Factor analysis offers a way of identifying differences among numerous original items using fewer created categories (i.e., factors) and assists in defining the substantive content or meaning of the factors that account for the differences among a large set of items (Fabrigar et al., 1999; Thompson, 2004). A Principal Components Analysis (PCA) with varimax rotation was used to provide maximal separation of factors. The PCA yielded 11 components with eigenvalues over 1.0, which accounted for $61.17 \%$ of the total variance. The initial eigenvalues ranged from 6.76 to 1.01 . Following rotation, they ranged from 3.36 to 1.41 . The percent of variance explained by each factor following rotation ranged from $8.40 \%$ to $3.53 \%$. Each factor was then described according to the predominant items that loaded on it. For the most part, factors comprised items that were easily grouped into categories. Factor scores were created by taking the mean of the items that loaded on each factor. Each scale was composed of two to seven items. Factor analysis highlights the main gratifications obtained by Saudi university students from using Facebook. Using this procedure, the 40 original items were grouped into 11 major factors that illustrate the Facebook-obtained gratifications. Cronbach's alpha reliabilities were then calculated for each of the factor scores. Cronbach's alpha is calculated from items' average inter-item correlations to indicate internal consistency of factor scores.

It is not surprising to note that the main reason that Saudi university students use Facebook is to communicate with 
friends. This accords with similar findings from other cultures (e.g., Bonds-Raacke \& Raacke, 2010; Ezumah, 2013; Patra, Gadekar, \& Krishnatray, 2013), and accords with Facebook's original purpose (to allow Harvard students to communicate with each other), which was later extended first to other university students, then to high school students, and finally, to all people over the age of 13 (Young, 2011). Saudi university students use Facebook mainly to connect, reconnect and maintain relationships with different circles of friends.

Entertainment was ranked the second highest gratification and has also been cited in most of the previous uses and gratifications studies on Facebook (e.g., Park, Kee, \& Valenzuela, 2009; Urista, Dong, \& Day, 2009; Quan-Haase \& Young, 2010; Alemdar \& Köker, 2013; Dhaha \& Igale, 2013; Ezumah, 2013; Ku, Chen, \& Zhang, 2013). It has also been revealed by studies that examined the usage of Web 1.0 by Saudi samples (e.g., Al-Saggaf, Weckert, \& Williamson, 2002). This gratification is composed of two elements: game playing and enjoying funny apps. Books (2014) argues that the entertainment aspect, particularly game-playing, is one of the main attractions enticing individuals to use Facebook, and more than half of the users worldwide seek this gratification, with a large percentage playing games on a daily basis.

The third most frequent Facebook-obtained gratification related to emotion. This factor includes three items: talking about emotional problems, letting feelings out, and sympathising with others. According to Morehouse and Crandall (2014), the introduction of Facebook provided a new form of emotional outlet, allowing users to reach out and often receive solace from others. It seems that Saudi students have found Facebook to be a new outlet which allows them to discuss their emotions and show sympathy with a wider circle of people. Ranked as the third obtained gratification factor, this result aligns with Walther, Slovacek, and Tidwell's (2001) argument that people are more likely to let out sensitive feelings and issues behind the protection of a screen than in offline settings. Besides, Facebook provides an easy opportunity that Saudi's did not have before.

Romance was the fourth gratification Saudi university students obtained from using Facebook. Three items were included in this factor: developing and maintaining romantic relationships, and sharing experiences about romantic relationships. They also swapped stories and shared romantic quotations from poetry, sayings, and songs that matched their romantic experiences.

The fifth gratification relates to the ability to share personal updates. This includes seven items relating to notifying others about current and recent activities, location, achievements, celebrations and events, and vacation details. Here Facebook provides a new channel for individuals to broadcast and share personal updates about what they are reading, thinking, and experiencing. According to Deng, Bispo, and Zeng (2014), social media users have a great motivation to keep their contacts informed about their activities. The gratification of sharing personal updates has been also mentioned in previous studies (e.g., Alemdar \& Köker, 2013; Dhaha \& Igale, 2013). It should be noted that in sharing such updates, an individual may reveal additional personal information either consciously or unconsciously. Thus, further investigation is needed about issues related to online disclosure.

Maintaining family relations was ranked sixth among Saudi students' obtained gratifications. This factor included two items: keeping in touch with family members and interacting with one's extended family. According to Long (2005), family is considered the most important social institution in Saudi society. The importance of family ties is based on cultural and Islamic values held by Saudis, which assert that individuals must keep continuous contact with other members of their nuclear and extended families and pursue all possible means of maintaining close ties with them. The data show that young Saudi Facebook users have a positive attitude towards contacting family, and employ Facebook as a new means of keeping in touch with them. However, it should be noted that the current sample consisted of individuals in their early twenties, most of whom still live with their families (83.1\%), which might explain why this only ranked midway in the list of gratifications.

Finding out about others was the seventh highest gratification, comprising five elements: 'Explore Facebook profiles that are not in my list', 'Find out more about someone I heard about', 'Find out what someone looks like', 'Find contact information for people I met offline', and 'Find out more about popular figures'. According to Darvell, Walsh, and White (2011), Facebook provides a significant opportunity for people to inspect and investigate other users' activities, enabling access to their photos, personal information, opinions and discussions. Thus, this platform can be used for surveillance, allowing users to track the actions of others and to find information about people outside of their networks (Lampe, Ellison, \& Steinfield, 2006). A Turkish study confirmed this disposition towards surveillance on social media, arguing that generation $\mathrm{Y}$ considers social surveillance, or attempting to collect information about other users without their knowledge, a significant gratification gained from using Facebook (Alemdar \& Köker, 2013).

Using Facebook for academic purposes was the eighth-ranked gratification, bringing together three items: 'Talking 
about studies', 'Learning a foreign language', and 'Joining academic groups'. Previous research has investigated the role of Facebook in students' lives and how it has been utilised to enhance pedagogical outcomes (Duffy, 2011). In this research, the students indicated that they use Facebook for a number of academic gratifications. According to Schroeder and Greenbowe (2009), Facebook can be used to improve learning by promoting communication, interaction, collaboration, and resource sharing. The efficacy of practicing and improving foreign languages through social media has also been confirmed by a study conducted by Kabilan, Ahmad, and Abidin (2010).

Communicating about social issues was the ninth obtained gratification. The opportunity to discuss social issues in a semi-public sphere is considered a relatively new experience for users. Six items are covered in this category: 'Discussing' and 'Documenting' social issues, 'Asking questions' and 'Raising awareness' of social issues, 'Joining a social cause', and engaging in 'Social criticism'. McGrath (1980) defines social issues as aspects that are connected with the running of society. He proposed three key categories of social issues: (1) Population (e.g., matters related to age, sex, nationality, ethnicity, socio-economic status, and disability), (2) Settings (e.g., matters concerning health, family, culture, and social change), and (3) Processes or behaviours (e.g., matters related to human rights, bias, prejudice, cruelty, fairness, attitude change, social mobility, morals, and the influence of these organisational procedures on the social lives of people). In terms of this research, this gratification related to the discussion of issues related to individuals' rights, social reform, and social criticism, which matches to some extent McGrath's third category.

The tenth gratification concerned communications about political issues. It consisted of two elements: 'Discussion of global political events' and 'Revealing opinions about local political events'. Saudi university students utilised Facebook to express their opinions and discuss news about current local and global events with others. As this research was conducted during a heated time in the Middle East, it seems that Facebook allowed individuals to effortlessly communicate about political issues without geographical constraints. They indicated that Facebook facilitated discussion of events in Arab countries and the sharing of opinions regarding political issues. As communicating about both social and political issues was not covered in the previous uses and gratifications literature, further investigation regarding these issues is conducted in the following phases.

The last Facebook-obtained gratification related to 'e-commerce', including buying, selling, and looking at advertisements. According to a market study by Stieglitz and Dang-Xuan (2012), Facebook enables users to obtain information about a product, including other users' testimonials regarding the quality of products. Its marketing techniques have been used to create and spread persuasive, targeted online messages that aim to stimulate customers to write positively about brands, products, and services (Kirby \& Marsden, 2006). However, this was not one of the most significant gratifications in this sample.

This research contributes to the body of uses and gratifications research by revealing 11 distinct and independent Facebook-obtained gratification factors that represent a complex and nuanced taxonomy of Facebook gratifications. It models a detailed process that can be followed by other researchers to validate their findings. The use of factor analysis has enabled the construction of 11 summary factors from the list of 40 individual gratifications surveyed in the questionnaire. This methodology illustrates the functional similarity among these 40 Facebook-obtained gratifications. These factors would not have emerged if the questionnaire had not been long and specific. They represent a significant improvement on the poorly worded, defined and formatted lists produced by some previous research. Although some of the categories appear similar to those revealed in previous studies, they might not be totally equivalent in different cultures. For example, although friendship was described in previous studies, friendship in Saudi culture refers solely to same-sex relationships. On the other hand, social and political issues have been given very little coverage in the uses and gratifications literature. This may be because it is a recent development, or because it was not included in top-down checklists.

The second research objective was to contribute to the theoretical and empirical literature on media and communication by producing a typology of Saudi university student Facebook users. In media and communication studies, a typology of users may be defined as "categorisation of users into distinct user types that describes the various ways in which individuals use different media, reflecting a varying amount of activity/content preferences, frequency of use and variety of use" (Brandtzæg, 2010: 941). This section also presents the results and a discussion of the typology of the current Saudi sample based on their obtained gratifications, usage variables, and demographic variables. According to the definition presented by Barnes et al. (2007), constructing a typology requires the division of individuals into clusters depending on their distinctive behaviours or characteristics. In other words, the main objective of such a division is to classify the entirety of the individuals into subgroups.

Unlike previous literature, which has treated the users of a media tool as a homogenous community seeking to obtain 
the same gratifications from their usage, developing a typology of users enables an investigation of how different patterns of media behaviour may be associated with different types of users. Classifying media tool users into distinctive subgroups provides more precision in understanding and identifying users and measuring the heterogeneity of media behaviour. It also reveals the extent to which individuals differ in their digital competence. Given that there is a scarcity in the literature on this subject (Brandtzæg \& Heim, 2011), investigating the nature of social media users' behaviour and unique user groups is a challenge, and more empirical research is needed to provide a better understanding of this relatively new media platform (Brandtzæg \& Heim, 2011).

The most prominent, and perhaps the only, proposed typology for users of social media platforms is provided by Brandtzæg (2010), who based his classification on a meta-analysis of the studies conducted on media user typologies and then tried to test the applicability of this typology on users of social media platforms (Brandtzæg \& Heim, 2011; Brandtzæg Heim., \& Karahasanović, 2011). According to Brandtzæg's (2010) typology, social media users vary based on frequency of use, type of activity, and social capital as follows: (1) sporadics "are low-level users of social media"; (2) lurkers "use social media, but do not contribute or interact"; (3) socialisers "use social media mainly for social interaction with friends and family"; (4) debaters "use social media mainly for discussion", and (5) advanced users "use social media frequently for almost all purposes, such as socializing, debating, and contributing" (Brandtzæg \& Heim, 2011: 41-42). While this typology can assist in understanding and categorising the increasingly complex behaviours found on social media platforms, it only focuses on users' degree of involvement on these platforms. The current research, by contrast, aims to also consider the diverse gratifications obtained from the users' degree of involvement and the effects of both their demographic backgrounds and usage differences on such gratifications.

Cluster analysis was employed to search for user types based on the gratification factors identified, with each type having a distinctive pattern of Facebook-obtained gratifications. Two-step cluster analysis was used with the 11 Facebook factors as clustering variables. This statistical method was chosen as a suitable approach for clustering large data sets with combined attributes (Norusis, 2003). It depends on a distance measure that allows data with both continuous attributes and categorical attributes to be grouped. According to Hsu, Chen \& Su (2007: 4477), "[this] technique is derived from a probabilistic model in which the distance between two clusters is equivalent to the decrease in log-likelihood function as a result of merging".

In order to perform a two-step cluster analysis, initial cases are categorised into pre-clusters that are then substituted in place of the raw data in the hierarchical clustering. According to its similarity to existing pre-clusters, each successive case is added to make a new pre-cluster, utilising a likelihood distance measure as the similarity criterion. Cases are allocated to the pre-cluster that increases a log-likelihood function. They are then clustered utilising the standard agglomerative clustering algorithm, forming a range of solutions. According to Okazaki (2006: 131), Schwarz's Bayesian Inference Criterion (BIC) is considered "one of the most useful and objective selection criteria that essentially avoid the arbitrariness in traditional clustering techniques". It helps in reducing this range of solutions to the best number of clusters.

The BIC is calculated for the potential number of clusters. Smaller values of the BIC mean better models. The BIC for three clusters was 2650.958 and slightly smaller for four clusters at 2643.656. However, the ratio of BIC changes was only .038 between three and four clusters, whereas the ratio change was highest for three clusters .619. Similarly, the ratio of distance measures was highest for three and four clusters. The best solution is one that has a large ratio of BIC changes and a large ratio of distance measures. The improvement in the BIC between three and four clusters was deemed insignificant and not worth the higher level of complexity caused by an additional cluster in the model (SPSS, 2012). Thus, three clusters were retained. Cluster 1 included 106 respondents (28.5\%), 186 respondents were placed in Cluster $2(50 \%)$ and 80 respondents were assigned to Cluster $3(21.5 \%)$.

One-way Analyses of Variance (ANOVAs) were used to evaluate whether there were significant differences in the cluster means on the Facebook-obtained gratification factors. Each of the clusters was significantly different (at $\mathrm{p}$ $<.001$ ), indicating that they each contributed some variance to the separation of the clusters. Post-hoc testing was then used to determine where the differences between clusters existed on each of the factors. Cluster 1 had the lowest means on each of the factors.

Between-cluster and within-cluster predictor importance charts were examined in order to reveal which variables were significant to the differentiation of each cluster. According to SPSS (2012), the null hypothesis for within-cluster importance of a continuous variable is that the mean in a cluster is the same as the overall mean. A variable's t-statistic and associated p-value are used to determine its within-cluster importance. Positive t-statistics indicate that the value generally takes a larger-than-average value in a particular cluster, whereas negative statistics 
indicate that the variable takes a smaller-than-average value.

The analysis shows that all the factors in Cluster 1 were lower than average, with each of them contributing significantly to the construction of the cluster. Thus, Cluster 1 participants are characterized as infrequent users of Facebook in terms of their scores on all of the 11 Facebook-obtained gratification factors. In Cluster 2, most of the gratifications took on values that were above average. The exceptions were communicating about social issues and political issues, which were below average but non-significant. On the other hand, communicating about social issues and political issues were the important factors in Cluster 3, with values higher than average. The remaining factors were either significantly below average or not significant contributors to the formation of Cluster 3 . Thus, users in Cluster 3 are characterised by using Facebook primarily for discussing social and political issues. Members of each cluster were then compared based on the independent variables presented perviously to evaluate if these identifiable subgroups differed in their backgrounds or usage variables.

The results showthat Cluster 3 has the highest percentage of males when compared to the other two clusters. Users in Cluster 2 have the highest economic status (i.e. upper middle class), followed by Cluster 1, which can be classified as middle class, and then by Cluster 3, which falls into the lower class. Regarding the adoption of Facebook, users in Cluster 1 started to use Facebook earlier than the other two clusters and thus could be viewed as early adopters. Cluster 2 represented mid-range adopters in terms of their experience of using Facebook, and users in the third cluster are considered late adopters of Facebook. In terms of time spent on Facebook, users of Cluster 1 can be considered medium users, Cluster 2 heavy users, and Cluster 3 light users. Based on these findings, the Facebook Saudi users are classified as follows:

\section{Cluster 1: Broad Nominal Users (28.5\%)}

Users in this cluster are termed Broad Nominal Users because they are infrequent users of Facebook in terms of their scores on all of the 11 Facebook-obtained gratification factors who use Facebook for an average time. Users in this cluster belong to the middle class, who tend to satisfy a range of diverse needs on Facebook without directing their usage towards specific activities. Broad Nominal Users are also characterised as being early adopters, and their years of experience utilising Facebook may explain their use of this platform to satisfy a variety of needs. Being early adopters may also explain why these users spent an average amount of time using Facebook, as they are used to it and consider it an intrinsic part of their daily lives. This result corresponds with the findings of Boyd and Heer (2006), who indicated that while early adopters updated their profiles regularly, they tended to log on less frequently.

\section{Cluster 2: High Selective Users (50\%)}

High Selective Users formed the largest category, accounting for half of all users. They gratified selective needs when using Facebook: communicating with friends, entertainment, emotional outlet, romance, sharing personal updates, communicating with family, investigating others, academic purposes, and shopping. They spend the largest amount of time on Facebook, but do not communicate about social or political issues. Thus, they could also be named general social users. Users in this cluster generally had the highest family income which may influence how they use Facebook. Another characteristic of these users is that they adopted Facebook along with the majority of people, i.e. neither early nor late.

\section{Cluster 3: Restricted Users (21.5\%)}

Users in this cluster are termed 'Restricted Users' because they devote their usage to communicating about social and political issues and ignore Facebook's other affordances. More than two-thirds of this cluster are males. Devoting their time to communicating about political and social issues, they do not make use of the other aspects of Facebook. This segment of users is also characterised by having the lowest family income and the lowest percentage of users.

Within his cute cat theory, Zuckerman (2014) argues that individuals may benefit from using social media platforms designed mainly for 'cute cat' purposes (a term used for any online activity which is popular but not serious) to generate and interact about political content. Applying this argument to the current categorisation of users, it can be argued that High Selective Users use Facebook for cute cat purposes. They represent half of the users (50\%) who joined Facebook to obtain gratifications, such as communicating with friends, entertainment, and shopping. Restricted Users, by contrast, can be classified as non-cute cat users, as they mainly focus their usage of Facebook on gratifying their needs for communicating about social and political issues. They represent the smallest percentage of the entire sample (21.5\%) that joined Facebook most recently. Broad Nominal Users seek to obtain both cute cat and non-cute cat gratifications from their usage of Facebook.

Moreover, it seems that there is a relationship between the gratifications, the time users spend on Facebook and their 
economic status. High Selective Users, who utilise Facebook to gratify a variety of needs (but not the discussion of social and political issues), are heavy users and have the highest economic status. In contrast, Restricted Users, who are light users and have the lowest income, devote their usage mainly to communicating about social and political issues. The characteristics of the typology of Facebook users show the different ways individuals use Facebook across the range of their obtained gratifications, demographic variables and usage variables.

\section{Conclusion}

This research aimed to develop an understanding of the gratifications Saudi university students obtain from using Facebook and construct a typology of these Facebook users. Through a quantitative questionnaire, data was collected from a representative sample of Saudi university students regarding their demographic backgrounds, Facebook usage, and obtained gratifications. The questionnaire developed in this research provides a comprehensive tool based on previous studies. This research adds a cultural dimension to applications of uses and gratifications theory in social media studies, as it reveals that Saudi users from an Islamic society utilise Facebook in a distinct way. Besides using Facebook to obtain a diverse range of gratifications, including personal, recreational, and academic, the findings reveal that Facebook provides an opportunity for Saudi university students to communicate about social and political issues. It is noteworthy that these gratifications have not been revealed in previous studies.

Previous studies of social media usage have generated lists of gratifications obtained from social media but have not shown how users within the same sample differ in these gratifications. This research contributes to the media and communication literature regarding the diversity and inequality of usage patterns of the same media tool across different sub-groups of users by presenting a typology of Facebook users based on their obtained gratifications, demographic characteristics, and usage differences. Three clusters of Facebook users emerged: Broad Nominal Users, who utilise Facebook to meet a wide range of gratifications; High Selective Users, who use the platform mainly for general gratifications without engaging in social and political issues, and Restricted Users, who use it to discuss current affairs.

\section{References}

Al-Saggaf, Y., Weckert, J., and Williamson, K. (2002) 'What Do Individuals in Saudi Arabia Say About their Participation in Online Communities'. in IADIS International Conference WWW/Internet. held 13-15 November at the IST Congress Center, Lisbon, Portugal

Alemdar, M. Y., \& Köker, N. E. (2013). Facebook Use and Gratıficatıons: A Study Directed to Determining the Facebook Usage of Generations X and Y in Turkey. Mediterranean Journal of Social Sciences, 4(11), 238. https://doi.org/10.5901/mjss.2013.v4n11p238

Alhabash, S., Chiang, Y. H., \& Huang, K. (2014). MAM \& U\&G in Taiwan: Differences in the Uses and Gratifications of Facebook as a Function of Motivational Reactivity. Computers in Human Behavior, 35, 423-430. https://doi.org/10.1016/j.chb.2014.03.033

AlMunajjed, M. (2008). Saudi Women Speak: 24 Remarkable Women Tell Their Success Stories. London: Arab Institute for Research and Publishing.

Arab Social Media Report (2016). A Report on Facebook Usage: Factors and Analysis, 1(1). Retrieved 17 September 2016, from http://unpan1.un.org/intradoc/groups/public/documents/dsg/unpan044212.pdf

Baki, R. (2004). Gender-Segregated Education in Saudi Arabia: Its Impact on Social Norms and the Saudi Labor Market. Education Policy Analysis Archives, 12(28), 22-35. https://doi.org/10.14507/epaa.v12n28.2004

Barkhuus, L., \& Tashiro, J. (2010). Student Socialization in the Age of Facebook. In Mynatt, E. (Ed.), Proceedings of the SIGCHI Conference on Human Factors in Computing Systems, 10-15. April Atlanta, GA, USA. https://doi.org/10.1145/1753326.1753347

Barnes, S. B. (2006). A privacy paradox: Social networking in the United States. First Monday, 11(9). https://doi.org/10.5210/fm.v11i9.1394

Bonds-Raacke, J., \& Raacke, J. (2010). MySpace and Facebook: Identifying Dimensions of Uses and Gratifications for Friend Networking Sites. Individual Differences Research, 8(1), 27-33.

Boogart, M. (2006). Uncovering the Social Impacts of Facebook on a College Campus. Unpublished dissertation. Lawrence, KS: University of Kansas.

Books, C. I. M. M. (2014) NEW! Unstoppable Facebook Traffic 2014: The Mega Effective Facebook Marketing Strategies 2014. CIMM Books 
Boyd, D. (2007). Error: You Must Be Someone's Friend to Comment on Them. In Proceedings of the 57 $7^{\text {th }}$ annual conference of International Communication Association, held 24-28 May at San Francisco, CA, USA.

Boyd, D. (2012). The Politics of Real Names. Communications of the ACM, 55(8), 29-31. https://doi.org/10.1145/2240236.2240247

Boyd, D., \& Heer, J. (2006, January). Profiles as conversation: Networked identity performance on Friendster. In System Sciences, 2006. HICSS'06. Proceedings of the 39th Annual Hawaii International Conference on (Vol. 3 , pp. 59c-59c). IEEE.

Brandtzæg, P. B. (2010). Towards a unified Media-User Typology (MUT): A meta-analysis and review of the research literature on media-user typologies. Computers in Human Behavior, 26(5), 940-956. https://doi.org/10.1016/j.chb.2010.02.008

Brandtzaeg, P. B., \& Heim, J. (2011). A typology of social networking sites users. International Journal of Web Based Communities, 7(1), 28-51. https://doi.org/10.1504/IJWBC.2011.038124

Brandtzæg, P. B., Heim, J., \& Karahasanović, A. (2011). Understanding the new digital divide-A typology of Internet users in Europe. International journal of human-computer studies, 69(3), 123-138. https://doi.org/10.1016/j.ijhcs.2010.11.004

Breyer, J., \& Zuckerberg, M (2005). Mark Zuckerberg Discusses Facebook. [Video Recording]. Retrieved 5 December 2013, from http://ecorner.stanford.edu/authorMaterialInfo.html?mid=1567

Bumgarner, B. A. (2007). You Have Been Poked: Exploring the Uses and Gratifications of Facebook among Emerging Adults. First Monday, 12(11). https://doi.org/10.5210/fm.v12i11.2026

Chou, H. T. G., \& Edge, N. (2012). They are Happier and Having Better Lives Than I am: the Impact of Using Facebook on Perceptions of Others' Lives. Cyberpsychology Behavior, and Social Networking, 15(2), 117-121. https://doi.org/10.1089/cyber.2011.0324

Condella, C. (2012). Why Can't We be Virtual Friends?. In Wittkower, D. (Ed.), Facebook and Philosophy: What's on Your Mind (pp. 111-121). Illinois: Open Court Publishing.

Darvell, M. J., Walsh, S. P., \& White, K. M. (2011). Facebook tells me so: Applying the theory of planned behavior to understand partner-monitoring behavior on Facebook. Cyberpsychology, Behavior, and Social Networking, 14(12), 717-722. https://doi.org/10.1089/cyber.2011.0035

Debatin, B., Lovejoy, J. P., Horn, A.K., \& Hughes, B. N. (2009). Facebook and Online Privacy: Attitudes, Behaviors, and Unintended Consequences. Journal of Computer-Mediated Communication, 15, 83-108. https://doi.org/10.1111/j.1083-6101.2009.01494.x

Deng, X., Bispo, C. B., and Zeng, Y. A. (2014). Reference Model for Privacy Protection in Social Networking Service. Journal of Integrated Design and Process Science 18 (2), 23-44

Dhaha, I. S. Y., \& Igale, A. B. (2013). Facebook usage among Somali youth: A test of uses and gratifications approach. International Journal of Humanities and Social Science, 3(3), 299-313.

Duffy, P. (2010). Facebook or Faceblock: Cautionary Tales Exploring. Web 2.0-Based E-Learning: Applying Social Informatics for Tertiary Teaching: Applying Social Informatics for Tertiary Teaching, 284.

Ellison, N. B., Steinfield, C., \& Lampe, C. (2007). The Benefits of Facebook "Friends:" Social Capital and College Students' Use of Online Social Network Sites. Journal of Computer-Mediated Communication, 12(4), 1143-1168. https://doi.org/10.1111/j.1083-6101.2007.00367.x

Ezumah, B. A. (2013). College students' use of social media: Site preferences, uses and gratifications theory revisited. International Journal of Business and Social Science, 4(5).

Fabrigar, L. R., Wegener, D. T., MacCallum, R. C., \& Strahan, E. J. (1999). Evaluating the use of exploratory factor analysis in psychological research. Psychological methods, 4(3), 272. https://doi.org/10.1037/1082-989X.4.3.272

Goel, V. (2014). Facebook to Ease Policies on Using Real Names for Accounts. The New York Times [online] 1 October. http://bits.blogs.nytimes.com/2014/10/01/facebook-agrees-to-ease-rules-on-real-names/?_php=true\&_type=blog 
S\&_r $=0$

Gomes, J. C. G., Matos, E., \& Duarte, C. (2014). A Survey about Media Content Consumption in Social Network Platforms. Research Gate, 1-4.

Heng, W. (2009). Communication with Saudis. Asian Social Science, 4(11), 124-130. https://doi.org/10.5539/ass.v4n11p124

Hew, K. F., \& Cheung, W. S. (2012). Use of Facebook: A Case Study of Singapore Students' Experience. Asia Pacific Journal of Education, 32(2), 181-196. https://doi.org/10.1080/02188791.2012.685560

Hsu, C. C., Chen, C. L., \& Su, Y. W. (2007). Hierarchical clustering of mixed data based on distance hierarchy. Information Sciences, 177(20), 4474-4492. https://doi.org/10.1016/j.ins.2007.05.003

Hum, N. J., Chamberlin, P. E., Hambright, B. L., Portwood, A. C., Schat, A. C., \& Bevan, J. L. (2011). A Picture is Worth a Thousand Words: A Content Analysis of Facebook Profile Photographs. Computers in Human Behavior, 27(5), 1828-1833. https://doi.org/10.1016/j.chb.2011.04.003

Joinson, A. N. (2008). Looking at, Looking up or Keeping up with People? Motives and Use of Facebook. In Proceedings of the SIGCHI conference on Human Factors in Computing Systems, held 5-10 April at Florence, Italy. New York, NY: ACM Press, 1027-1036.

Kabilan, M. K., Ahmad, N., \& Abidin, M. J. Z. (2010). Facebook: An online environment for learning of English in institutions of higher education?. The Internet and higher education, 13(4), 179-187. https://doi.org/10.1016/j.iheduc.2010.07.003

Kaplan, A. M., \& Haenlein, M. (2010). Users of the World, Unite! The Challenges and Opportunities of Social Media. Business Horizons, 53(1), 59-68. https://doi.org/10.1016/j.bushor.2009.09.003

Kasavana, M. L., Nusair, K., \& Teodosic, K. (2010). Online social networking: redefining the human web. Journal of Hospitality and Tourism Technology, 1(1), 68-82. https://doi.org/10.1108/17579881011023025

Khannous, T. (2011). Virtual Gender: Moroccan and Saudi Women's Cyberspace. Hawwa, 9(3), $358-387$. https://doi.org/10.1163/156920811X599121

Kirby, J., \& Marsden, P. (Eds.). (2006). Connected marketing: the viral, buzz and word of mouth revolution. Elsevier

Ku, Y. C., Chen, R., \& Zhang, H. (2013). Why do users continue using social networking sites? An exploratory study of members in the United States and Taiwan. Information \& Management, 50(7), 571-581. https://doi.org/10.1016/j.im.2013.07.011

Lampe, C., Ellison, N., \& Steinfield, C. (2006, November). A Face (book) in the crowd: Social searching vs. social browsing. In Proceedings of the 2006 20th anniversary conference on Computer supported cooperative work (pp. 167-170). ACM. https://doi.org/10.1145/1180875.1180901

Leung, L. (2014). Predicting Internet Risks: A Longitudinal Panel Study of Gratifications-Sought, Internet Addiction Symptoms, and Social Media Use among Children and Adolescents. Health Psychology and Behavioral Medicine Journal, 2(1), 424-439. https://doi.org/10.1080/21642850.2014.902316

Leung, L. (2014). Predicting Internet Risks: A Longitudinal Panel Study of Gratifications-Sought, Internet Addiction Symptoms, and Social Media Use among Children and Adolescents. Health Psychology and Behavioral Medicine Journal, 2(1), 424-439. https://doi.org/10.1080/21642850.2014.902316

Lewis, J., \& West, A. (2009). Friending: London-based Undergraduates' Experience of Facebook. New Media \& Society, 11(7), 1209-1229. https://doi.org/10.1177/1461444809342058

Long, D. E. (2005). Culture and customs of Saudi Arabia. Penn State Press.

Lovink, G. (2013). A World Beyond Facebook: Alternatives in Social Media: The Research Agenda of the Unlike Us Network. Mediascapes Journal, 1, 58-64.

Madini, A. (2012). Online Communication in a Discussion Forum for Expatriate Saudi Arabian Students: Gender Issues. Unpublished PhD thesis. Brisbane: The University of Queensland.

McCarty, C. (2002). Structure in Personal Networks. Journal of Social Structure [online] 3(1). Retrieved from http://www.cmu.edu/joss/content/articles/volume3/McCarty.html 
McCorkindale, T., DiStaso, M. W., \& Sisco, H. F. (2013). How Millennials Are Engaging and Building Relationships with Organizations on Facebook. The Journal of Social Media in Society, 2(1), 66-86.

McGrath, J. E. (1980). What are the Social Issues?: Timeliness and Treatment of Topics in the Journal of Social Issues. Journal of Social Issues, 36(4), 98-108.

Miladi, N. (2011). New media and the Arab Revolution: Citizen Reporters and Social Activism. Journal of Arab and Muslim Media Research, 4(2/3), 3-5.

Ministry of Higher Education (2013). The Condition of Higher Education in Saudi Arabia. Riyadh: Ministry of Higher Education.

Mishra, S., Draus, P. J., Leone, G. J., \& Caputo, D. J. (2012). Exploring Underlying Factors Influencing Daily Usage of Facebook for Undergraduate College Students: A Research Model. Issues in Information Systems, 13(1), 350-360.

Moaddel, M. (2013). The Birthplace of the Arab spring: Values and Perceptions of Tunisians and a Comparative Assessment of Egyptian, Iraqi, Lebanese, Pakistani, Saudi, Tunisian, and Turkish Publics. College Park, MD: University of Maryland.

Morehouse, K. J., and Crandall, H. M. (2014) 'Virtual Grief'. Communication Research Trends 33 (1), 26-28.

Noor Elahi, M. (2010). My Name; My Identity-What is Yours? A Saudi Woman's Voice. Retrieved from http://saudirevelations.wordpress.com/

Norusis, M.J. (2003) SPSS 12.0: Statistical Procedures Companion. Upper Saddle River, NJ: Prentice Hall.

Okazaki, S. (2006) 'What Do We Know About Mobile Internet Adopters? A Cluster Analysis'. Information \& Management 43 (2), 127-141. https://doi.org/10.1016/j.im.2005.05.001

Oshan, M. (2007). Saudi Women Student and the Internet: Gender and Culture Issues. Unpublished PhD thesis. Loughborough: Loughborough University.

Pai, P., \& Arnott, D. C. (2013). User Adoption of Social Networking Sites: Eliciting Uses and Gratifications through a Means-End Approach. Computers in Human Behavior, 29(3), 1039-1053. https://doi.org/10.1016/j.chb.2012.06.025

Park, N., Kee, K. F., \& Valenzuela, S. (2009). Being immersed in social networking environment: Facebook groups, uses and gratifications, and social outcomes. CyberPsychology \& Behavior, 12(6), 729-733.

Park, N., Kee, K., \& Valenzuela, S. (2009). Being Immersed in Social Networking Environment: Facebook Groups, Uses and Gratifications, and Social Outcomes. Cyber Psychology \& Behavior, 12(6), 729-733. https://doi.org/10.1089/cpb.2009.0003

Patra, S. K., Gadekar, R., \& Krishnatray, P. (2013). Users' Gratification, Self-Schema and Facebook Behaviour: A Study of Selective Young Facebook Users. Media Watch, 4(1), 84-94.

Pempek, T., Yermolayeva, A., \& Calvert, S. (2009). College Students' Social Networking Experiences on Facebook. Journal of Applied Developmental Psychology, 30, 227-238. https://doi.org/10.1016/j.appdev.2008.12.010

Pew Internet and American Life Project. (2010). Millennials: A Portrait of Generation. Washington, DC: Pew Internet and American Life Project. Retrieved 5 June 2012, from http://www.pewresearch.org/millennials/

Phillips, C. (2010). Millennials Tech-dependent, but not Necessarily Tech-savvy. Millennial Marketing Insights. Retrieved from http://millennialmarketing.com/2010/04/millennials-tech-dependent-but-not-necessarily-tech-savvy/

Quan-Haase, A., \& Young, A. L. (2010). Uses and gratifications of social media: A comparison of Facebook and instant messaging. Bulletin of Science, Technology \& Society, 30(5), 350-361. https://doi.org/10.1177/0270467610380009

Ross, C., Orr, E. S., Sisic, M., Arseneault, J. M., Simmering, M. G., \& Orr, R. R. (2009). Personality and Motivations Associated with Facebook Use. Computers in Human Behavior, 25(2), 578-586. https://doi.org/10.1016/j.chb.2008.12.024

Salam, A. A. (2013). Nuptiality and Fertility in Saudi Arabia: An Appraisal of Census Data. Middle East Fertility Society Journal, 18(3), 147-153. https://doi.org/10.1016/j.mefs.2013.04.006 
Samin, N. (2008). Dynamics of Internet Use: Saudi Youth, Religious Minorities and Tribal Communities. Middle East Journal of Culture and Communication, 1(2), 197-215. https://doi.org/10.1163/187398608X335838

Schroeder, J., \& Greenbowe, T. J. (2009). The chemistry of Facebook: Using social networking to create an online community for the organic chemistry laboratory. Innovate: Journal of Online Education, 5(4), 3.

Sheldon, P. (2008). The Relationship between Unwillingness-to-Communicate and Students' Facebook Use. Journal of Media Psychology: Theories, Methods, and Applications, 20(2), 67. https://doi.org/10.1027/1864-1105.20.2.67

SPSS (2012). IBM SPSS Statistics 20 Documentation [online] available from <http://www-01.ibm.com/support/docview.wss?uid=swg27021213\#en> [10 July 2012]

Stern, L., \& Taylor, K. (2007). Social Networking on Facebook. Journal of the Communication, Speech \& Theatre Association of North Dakota, 20, 9-20.

Stieglitz, S., \& Dang-Xuan, L. (2013). Social media and political communication: a social media analytics framework. Social Network Analysis and Mining, 3(4), 1277-1291. https://doi.org/10.1007/s13278-012-0079-3

Sweis, R., Zyod, D., \& Alshurideh, M. (2012). The Effect of Perceived Service Quality on Customer Loyalty in Internet Service Providers in Jordan. Journal of Management Research, 4(4), 224-242.

Taraszow, T., Arsoy, A., Shitta, G., \& Laouris, Y. (2008). How Much Personal and Sensitive Information Do Cypriot Teenagers Reveal in Facebook?. In Proceedings of the 7th European Conference on E-Learning, held 6-7 of November at Agia Napa, Cyprus, 871-876.

The Social Clinic. (2016). Saudi Arabia Trends. Retrieved 29 July 2017, from http://www.thesocialclinic.com/tag/saudi-arabia/

Thompson, B. (2004). Exploratory and confirmatory factor analysis: Understanding concepts and applications. American Psychological Association. https://doi.org/10.1037/10694-000

Tung, P., \& Scott, D. (2012). Social Media and Privacy: Comparing U.S. and Japanese College Students' Use of Facebook and Twitter. In T. Bastiaens \& G. Marks (Eds.), Proceedings of World Conference on E-Learning in Corporate, Government, Healthcare, and Higher Education, held 9-12 October at Montreal, Quebec, Canada.

Tung, P., \& Scott, D. (2012). Social Media and Privacy: Comparing U.S. and Japanese College Students' Use of Facebook and Twitter. In T. Bastiaens \& G. Marks (Eds.), Proceedings of World Conference on E-Learning in Corporate, Government, Healthcare, and Higher Education, held 9-12 October at Montreal, Quebec, Canada.

UNESCO. (2011). Gender-Sensitive Education Statistics and Indicators: A Practical Guide. Paris: United National Educational, Scientific and Cultural Organization.

UNICEF (2016). Saudi Arabia: Statistics. Retrieved 20 May 2017, from http://www.unicef.org/infobycountry/saudiarabia_statistics.html

Urista, M. A., Dong, Q., \& Day, K. D. (2009). Explaining Why Young Adults Use Myspace and Facebook through Uses and Gratifications Theory. Human Communication, 12(2), 215-229.

Veltri, N., \& Elgarah, W. (2009). The Role of National Culture Differences in User Adoption of Social Networking. In Proceedings of Twelfth Annual Conference of the Southern Association for Information Systems (SAIS), held 12-14 March at Charleston Southern University, North Charleston, SC, USA.

Vratskikh, I., Al-Lozi, M., \& Maqableh, M. (2016). The Impact of Emotional Intelligence on Job Performance via the Mediating Role of Job Satisfaction. International Journal of Business and Management, 69-91. https://doi.org/10.5539/ijbm.v11n2p69

Walther, J. B., Slovacek, C. L., \& Tidwell, L. C. (2001). Is a picture worth a thousand words? Photographic images in long-term and short-term computer-mediated communication. Communication Research, 28(1), 105-134. https://doi.org/10.1177/009365001028001004

Walther, J., Van Der Heide, B., Kim, S., Westerman, D., \& Tong, S. (2008). The Role of Friends' Appearance and Behavior on Evaluations of Individuals on Facebook: Are We Known by the Company We Keep?. Human Communication Research, 34, 28-49. https://doi.org/10.1111/j.1468-2958.2007.00312.x

Young, A., \& Quan-Haase, A. (2009). Information Revelation and Internet Privacy Concerns on Social Network 
Sites: A Case Study of Facebook. In Proceedings of The Fourth International Conference on Communities and Technologies, held 25-27 June at Penn State University, Park, PA, USA. https://doi.org/10.1145/1556460.1556499

Young, K. (2011). Social ties, social networks and the Facebook experience. International Journal of Emerging Technologies and Society, 9(1), 20.

Zhang, Y., Tang, L., \& Leung, L. (2011). Gratifications, Collective Self-Esteem, Online Emotional Openness, and Trait-like Communication Apprehension as Predictors of Facebook Uses. Cyberpsychology, Behavior, and Social Networking, 14(12), 733-739. https://doi.org/10.1089/cyber.2010.0042

Zuckerman, E. (2014). Cute Cats to the Rescue? Participatory Media and Political Expression. in Youth, New Media and Political Participation. eds. by Allen, D. and Jennifer, L. Cambridge, MA: MIT Press. 